\title{
Development and Characterization of an Electroless Plated Silver/Cysteine Sensor Platform for the Electrochemical Determination of Aflatoxin $B_{1}$
}

\author{
Alex Paul Wacoo, ${ }^{1,2}$ Mathew Ocheng, ${ }^{3}$ Deborah Wendiro, \\ Peter California Vuzi, ${ }^{2}$ and Joseph F. Hawumba ${ }^{2}$ \\ ${ }^{1}$ Microbiology and Biotechnology Centre, Department of Product Development, Uganda Industrial Research Institute, \\ P.O. Box 7086, Kampala, Uganda \\ ${ }^{2}$ Department of Biochemistry and Sports Science, School of Biological Sciences, College of Natural Sciences, Makerere University, \\ P.O. Box 7082, Kampala, Uganda \\ ${ }^{3}$ Instrumentation Unit, Technology Development Centre, Uganda Industrial Research Institute, P.O. Box 7086, Kampala, Uganda
}

Correspondence should be addressed to Joseph F. Hawumba; jhawumba@cns.mak.ac.ug

Received 25 March 2015; Revised 25 September 2015; Accepted 27 September 2015

Academic Editor: Banshi D. Gupta

Copyright (C) 2016 Alex Paul Wacoo et al. This is an open access article distributed under the Creative Commons Attribution License, which permits unrestricted use, distribution, and reproduction in any medium, provided the original work is properly cited.

An electroless plated silver/cysteine sensor platform [Glass|silver|cysteine|aflatoxin $B_{1} \mid$ horseradish peroxidase] for the Electrochemical detection of aflatoxin $B_{1}$ was developed and characterized. This involved four major steps: (1) an electroless deposition of silver (plating) onto a glass slide, (2) immobilization of cysteine; (3) conjugation of aflatoxin $\mathrm{B}_{1}$ to cysteine groups; and (4) blocking of free cysteine groups with horseradish peroxidase (HRP). The binding of cysteine to the silver was demonstrated by the disappearance of thiol (S-H) groups at $2500 \mathrm{~cm}^{-1}$ using Fourier transmittance infrared spectra (FT-IR), while the subsequent steps in the assembly of sensor platform were monitored using both FT-IR and cyclic voltammetry, respectively. The sensor platform exhibited a broadened nonsymmetrical redox couple as indicated by cyclic voltammetry. The platform was further characterized for sensitivity and limit of detection. The indirect competitive immunoassay format, whereby free and immobilized aflatoxin $\mathrm{B}_{1}$ on the sensor competed for the binding site of free anti-aflatoxin $B_{1}$ antibody, was used at various concentrations of aflatoxin $B_{1}$. The sensor generated differential staircase voltammogram that was inversely proportional to the concentration of aflatoxin $\mathrm{B}_{1}$ and aflatoxin $B_{1}$ in the range of $0.06-1.1 \mathrm{ng} / \mathrm{mL}$ with a detection limit of $0.08 \mathrm{ng} / \mathrm{mL}$ could be detected.

\section{Introduction}

Several methods have been described for the detection of aflatoxins in foodstuff and feeds [1]; including, among others, such methods as thin-layer chromatography (TLC), highperformance liquid chromatography (HPLC), and immunoassay based methods. Immunoassay methods, which became widely popular during late 1970s, rely on the specificity of binding between antibodies/receptors and antigens/ligands. The high affinity and specificity of antibodies/receptors for antigens/ligands have been used in the development of the various immunochemical methods [2]. The formation of either the antibody-antigen or the receptor-ligand complexes can be quantified by following the change in the absorbance of photons of light energy spectrophotometrically. In other instances, the binding events, as well as the resultant complexes, may require amplification for better signal recognition. This has been achieved by using various labels comprising enzymes (as for the enzyme-linked immunosorbent assay (ELISA)), fluorophores, and radioisotopes (as for the radioimmunoassay (RIA)), among others. The application of immunochemical methods for determining aflatoxin $B_{1}$ in peanuts was reported by Langone and Van Vunakis, [3] using solid phase radioimmunoassay (RIA). Several other investigators have also reported the use of monoclonal antibody in immunoaffinity column assay (ICA) and ELISA for 
determining aflatoxins in peanuts [4]. The advantages of immunoassays included high level of specificity and sensitivity even in the presence of contaminating materials and ease of sample preparation, as well as usage and low cost. However, the requirement for molecular labels, expensive equipment, and cumbersome multiple washing steps necessitated the development of more user-friendly devices.

Thus, immunosensors, which are biosensors that also rely on either antigen-antibody or receptor/ligand interaction to generate detectable signals, were developed. As a matter of fact, Immunosensors have proved to be self-sufficient integrated devices that use biological recognition element retained in direct spatial contact with a transduction element, to provide precise quantitative or semiquantitative results [5]. Moreover, immunosensors exhibit high sensitivities, with detection limits below $0.1 \mathrm{ng} / \mathrm{mL}$ [6]. Several electrochemical immunosensors have been developed through immobilization of antibodies onto the surface of an electrode and have been reported for detection of aflatoxins [7-9]. Nevertheless, some of them require labels for electrochemical transduction. To overcome the requirement of a label, labelfree biosensor platforms such as optical waveguide [10], surface plasmon resonance platforms [11, 12], and electrochemical immunosensor have been developed. Although the two label-free platforms are highly sensitive and with detectable ranges between 0.5 and $10 \mathrm{ng} / \mathrm{mL}$ for aflatoxins, the devices operating these platforms are still expensive and not deployable in the field [1]. The aim of the study was to develop and characterize an electroless plated silver/cysteine sensor platform operating on a label-free format, for the detection of aflatoxin $B_{1}$ in foodstuff and feeds, as well as the construction of a field-deployable devise operating on this platform appropriate for field analysis of aflatoxin $B_{1}$. The development and characterization of an electroless plated silver/cysteine sensor platform [glass|silver|cysteine|aflatoxin $\mathrm{B}_{1}$ |horseradish peroxidase-blocked] is herewith reported.

\section{Materials and Methods}

2.1. Reagents, Materials, and Apparatus. All chemicals and reagents used were purchased from Sigma and all were, unless stated, of analytical grade. Acetate buffer $(0.1 \mathrm{M}, \mathrm{pH}$ 6.5) was prepared from stock solutions of $\mathrm{CH}_{3} \mathrm{COONa}$, $\mathrm{CH}_{3} \mathrm{COOH}$, and $\mathrm{KCl}$. Silver ammonia $\left(\mathrm{Ag}\left(\mathrm{NH}_{3}\right)^{+}\right)$solution $(5 \%, \mathrm{w} / \mathrm{v})$ was prepared by dissolving $0.5 \mathrm{~g}$ of Silver nitrate in $10 \mathrm{~mL}$ of absolute ammonia solution. Sodium hydroxide $(10 \%, \mathrm{w} / \mathrm{v})$ was prepared by dissolving $5 \mathrm{~g}$ of $\mathrm{NaOH}$ in $50 \mathrm{~mL}$ of deionized water. Piranha solution contained 3 parts of concentrated sulphuric acid and 1 part of hydrogen peroxide in the ratio. D-glucose $(5 \%, \mathrm{w} / \mathrm{v})$ solution was prepared by dissolving $2.5 \mathrm{~g}$ of $\mathrm{D}$-glucose in $50 \mathrm{~mL}$ of distilled water. Lcysteine (analytical purity) was obtained from Nutritional Biochemical Corporation (USA). A solution of $10 \mu \mathrm{M}$ hydrogen peroxide was prepared from a stock solution of $30 \%$ $(\mathrm{v} / \mathrm{v})$ hydrogen peroxide solution. Aflatoxin $\mathrm{B}_{1}$ standard solution $(0.1-1.0 \mathrm{ng} / \mathrm{mL})$ was prepared by serial dilution of aflatoxin $B_{1}$ stock solution $(1 \mathrm{mg} / \mathrm{mL})$ in phosphate buffer saline (PBS) containing $10 \%(\mathrm{v} / \mathrm{v})$ methanol. The aflatoxin $\mathrm{B}_{1}$ monoclonal antibody reagent contained $6.8 \mathrm{mg} / \mathrm{mL}$ of total protein in $0.15 \mathrm{M}$ sodium azide $\left(\mathrm{NaN}_{3}\right)$ as preservative. The horseradish peroxidase (HRP) contained 169 units/mL of the lyophilized powder. Fourier Transform Infrared (FTIR) spectrophotometer (Perkin Elma, Massachusetts, USA) was used to generate FT-IR spectra. A three-electrode electrochemistry workstation developed locally at Instrumentation Unit, Technology Development Centre, Uganda Industrial Research Institute, was used to measure both cyclic voltammogram (CV) and differential staircase voltammogram (DSCV). The work station was connected to Arbitrary/Function Generator with counter (BK Precision, 4048, UK) and used to generate staircase and cyclic waves. Digital storage oscilloscope (BK Precision, 2540, UK) was used for data acquisition. Silver (Ag)/silver chloride $(\mathrm{AgCl})(3 \mathrm{M})$ was used as a reference. The $\mathrm{pH}$ measurements were performed with 827 Metrohm $\mathrm{pH}$ meter (Mettler Toledo, Switzerland). Acidified Tin IV chloride solution contained $12 \mathrm{mg} \mathrm{SnCl}, 0.05 \mathrm{~mL}$ hydrochloric acid, and $49.95 \mathrm{~mL}$ deionized (DI) water. Acidified silver nitrate solution contained $4 \mathrm{mg} \mathrm{AgNO}_{3}, 0.05 \mathrm{~mL} \mathrm{HCl}$, and $49.95 \mathrm{~mL}$ DI water. Modified Tollen's plating reagent contained $20 \%(\mathrm{w} / \mathrm{v})$ silver ammonia $\left(\mathrm{Ag}\left(\mathrm{NH}_{3}\right)^{2+}\right)$ solution, $2.5 \mathrm{~mL} 10 \%(\mathrm{w} / \mathrm{v})$ sodium hydroxide $(\mathrm{NaOH})$, and $2.5 \mathrm{~mL}$ of $5 \%(\mathrm{w} / \mathrm{v})$ D-glucose. Aflatoxin $\mathrm{B}_{1}$ immobilisation reagent prepared by $20 \mathrm{mg}$ of aflatoxin $\mathrm{B}_{1}$ dissolved in mixture of pyridine, methanol, and water in a ratio of $1: 4: 1$.

\subsection{Development of a Biosensor Platform}

2.2.1. Deposition of Silver on the Glass Slide. The first step in the development of the biosensor platform involved an electroless deposition of silver (plating) onto a glass slide (Figure 1, step 1). This is typically a wet chemical process that involved selective reduction of silver ions on a glass slide surface. Glass slides $(0.4 \times 1.5 \mathrm{~cm})$ were immersed sequentially, for $5 \mathrm{~min}$ each, in deionized water and $95 \%$ (v/v) ethanol followed by removal of organic impurities in a freshly prepared Piranha solution at $90^{\circ} \mathrm{C}$ for $30 \mathrm{~min}$. Thereafter, the slides were activated by $\mathrm{Sn}-\mathrm{Ag}$ in a twostep process [13]. The slides were first activated in acidified solution of Tin IV chloride, rinsed with deionized water and subsequently sensitized in another acidified solution of Silver nitrate $\left(\mathrm{AgNO}_{3}\right)$ for $25 \mathrm{~s}$. and finally rinsed, sequentially, in nitric acid containing deionized water, and with deionized water alone, to remove unbound $\mathrm{Sn}^{2+}$ compounds. The activated glass slides were immersed in $2 \mathrm{~mL}$ of modified Tollen's reagent plating solution and rinsed with DI water after $5 \mathrm{~min}$. This step was repeated six times [14]. Thereafter, the coated slides were air dried and annealed at $300^{\circ} \mathrm{C}$ for $6 \mathrm{~min}$ in a furnace under the atmosphere nitrogen. The immobilized/coated silver served as the transducer of the sensor platform. The surface of the annealed coated silver was monitored by using FT-IR between $400 \mathrm{~cm}^{-1}$ and $4,000 \mathrm{~cm}^{-1}$ at a scanning speed of $500 \mathrm{~nm} / \mathrm{min}$.

2.2.2. Assembly of the Immunosensor. The second phase in the development of the immunosensor platform involved three major steps: (1) immobilization of cysteine; (2) conjugation 

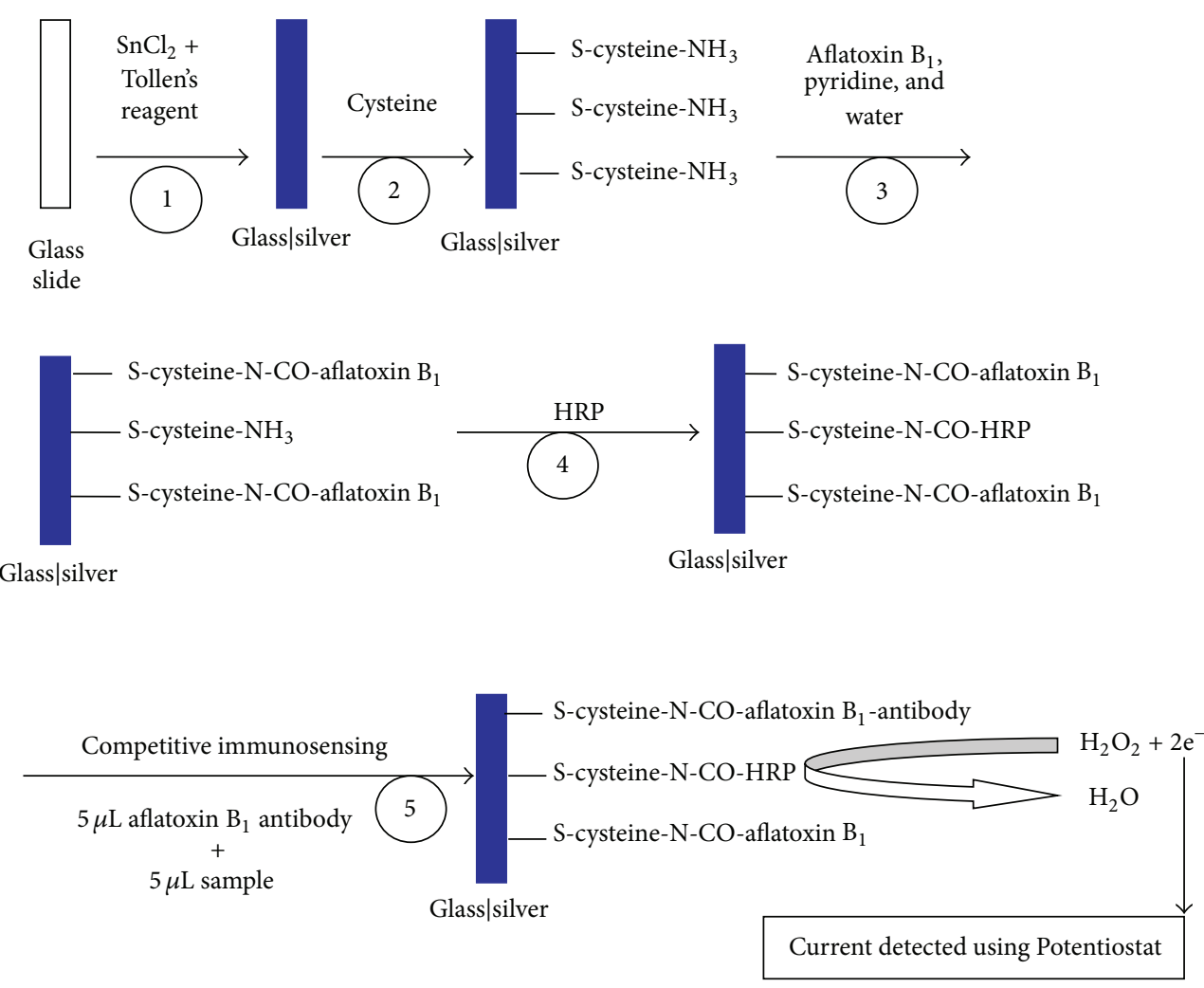

FIGURE 1: Representation of major steps in the assembly of the immunosensor platform. Step 1: electroless silver plating. Step 2: immobilization of cysteine. Step 3: conjugation of aflatoxin $B_{1}$ to cysteine groups. Step 4: blocking of aflatoxin $B_{1}$ layer with HRP. Step 5: competitive immunosensing of aflatoxin $\mathrm{B}_{1}$.

of aflatoxin $\mathrm{B}_{1}$ to cysteine groups; and (3) blocking of free cysteine groups (unconjugated to AFB1) with HRP. (Figure 1: steps 2 to 4). In order to functionalize the sensor platform, the annealed glass|silver was immersed in the saturated solution of L-cysteine for $12 \mathrm{~h}$, rinsed with distilled water, and finally dried in a stream of nitrogen gas and stored at $4^{\circ} \mathrm{C}$ as it awaits conjugation step. The conjugation of aflatoxin $B_{1}$ to cysteine groups immobilized onto the silver (transducer) involved an overnight incubation of the cysteine-functionalized glass/silver platform in an aflatoxin $\mathrm{B}_{1}$ immobilization reagent and thereafter the platform was washed several times in $0.1 \mathrm{M}$ phosphate buffer of $\mathrm{pH} 7.4$ to remove any residual monomer and weakly bound aflatoxin $B_{1}$ molecules. The unconjugated sites of cysteine on the resultant immunosensor platform were blocked by incubating it in $0.1 \mathrm{M}$ acetate buffer ( $\mathrm{pH}$ 6.5) containing $1 \mathrm{mg} / \mathrm{mL}$ HRP at $4^{\circ} \mathrm{C}$ for 15 hours. The sensor platform was subsequently washed in $0.1 \mathrm{M}$ phosphate buffer $(\mathrm{pH} 7.4)$, dried in a stream of nitrogen, and stored at $4^{\circ} \mathrm{C}$ until used. To make certain that the blocking step was successful, the prensence of HRP enzymes at the blocked sites was assayed using hydrogen peroxide as a substrate. The sensor was treated with $10 \mu \mathrm{M}$ hydrogen peroxide $\left(\mathrm{H}_{2} \mathrm{O}_{2}\right)$ in citrate buffer, $\mathrm{pH} 6.5$, and the activity of horseradish peroxidase, defined by its breakdown of $\mathrm{H}_{2} \mathrm{O}_{2}$ to water, oxygen, and two electrones, monitored by cyclic voltammetric scan. The scan was performed at a voltage ranging from 0 to $-1000 \mathrm{mV}$ at rate of $100 \mathrm{mV} / \mathrm{s}$. The FTIR spectra were measured between $400 \mathrm{~cm}^{-1}$ and $4,000 \mathrm{~cm}^{-1}$ at a scanning speed of $500 \mathrm{~nm} / \mathrm{min}$ at every stage of sensor platform development. In order to ascertain that the change in the chromatogram when the electroless plated silver is conjugated to cysteine, FT-IR spectrum of cysteine alone was also measured between $400 \mathrm{~cm}^{-1}$ and $4,000 \mathrm{~cm}^{-1}$ at a scanning speed of $500 \mathrm{~nm} / \mathrm{min}$ and plotted in the same graph for comparative purpose. For the electrochemical detection of aflatoxin $B_{1}$ using a competitive immunosensing format, the sensor platform (i.e., Glass|silver|cysteine|aflatoxin $\mathrm{B}_{1} \mid \mathrm{HRP}$ blocked) served as a working electrode. From henceforth, sensor electrode is synonymous to sensor platform.

2.3. Electrochemical Immune Detection of Aflatoxin $B_{1}$. In order to test the performance of the developed sensor platform for the detection of aflatoxin $\mathrm{B}_{1}$, the sensor platform served as a working electrode and a competitive immunosensing format (Figure 1; step 5) was performed both in the absence and presence of free aflatoxin $B_{1}$ [6]. In the absence of free aflatoxin $\mathrm{B}_{1}, 5 \mu \mathrm{L}$ aliquot of aflatoxin $\mathrm{B}_{1}$ antibody was bound onto the sensor electrode for $5 \mathrm{~min}$ and then the sensor was transferred to another $5 \mathrm{~mL}$ cell solution of $10 \mu \mathrm{M} \mathrm{H}_{2} \mathrm{O}_{2}$ in $0.1 \mathrm{M}$ acetate buffer $\mathrm{pH}$ 6.5. Differential staircase voltammetric measurement of the working electrode was performed by scanning from 0 to $600 \mathrm{mV}$ at $60 \mathrm{mV}$ pulse amplitude and $20 \mathrm{mV} / \mathrm{s}$ potential scan rate. For investigation in the presence of aflatoxin $\mathrm{B}_{1}$, aliquots of $5 \mu \mathrm{L}$ of anti-aflatoxin $\mathrm{B}_{1}$ antibody solution were mixed with $5 \mu \mathrm{L}$ 


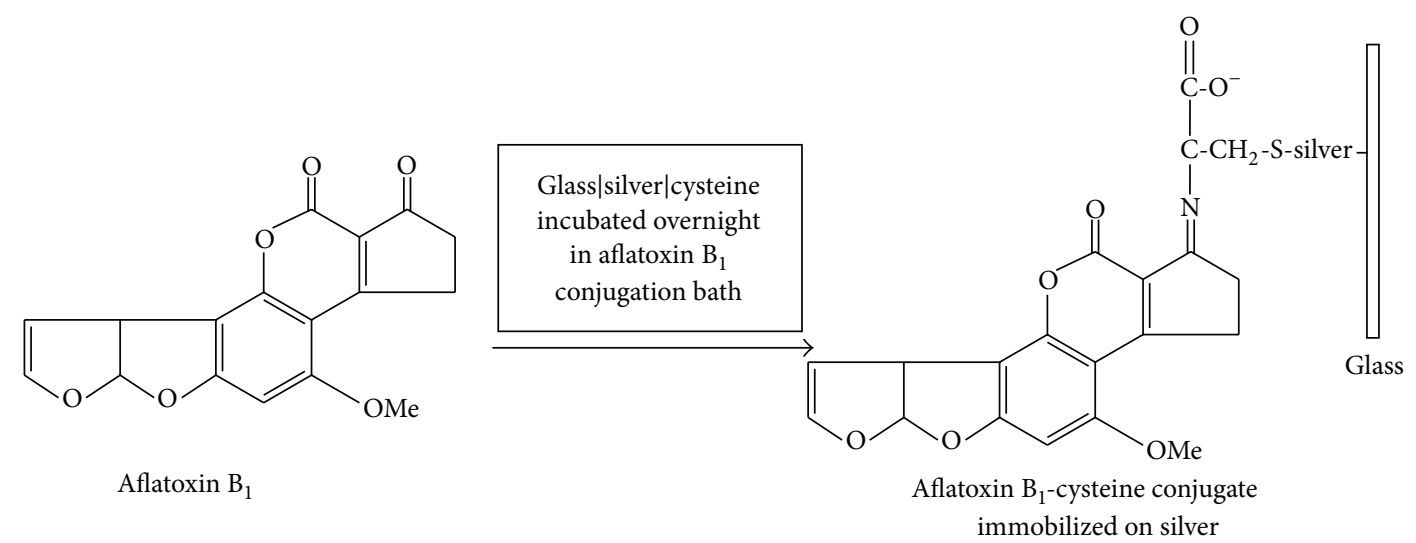

FIgURE 2: Preparation of aflatoxin $\mathrm{B}_{1}$-cysteine-silver conjugate.

each of $0.2,0.5,0.8$, and $1.0 \mathrm{ng} / \mathrm{mL}$ standard aflatoxin $\mathrm{B}_{1}$ in $70 \%(\mathrm{v} / \mathrm{v})$ methanol and $5 \mu \mathrm{L}$ each of the mixtures placed on sensor platform and allowed to react for $5 \mathrm{~min}$. This was followed by differential staircase voltammetric measurement as described above. In order to calibrate the sensor platform, the same experiment was repeated in triplicate and the peak heights at each concentration were plotted to obtain three calibration curves. The correlation coefficient $\left(R^{2}\right)$ and slope of the regression line of each curve were determined, and the limit of detection (LOD) was calculated from LOD = $(3.3 * \mathrm{SD}) /$ slope, where SD equals the standard deviation of correlation coefficient of 3 calibration curves and slope equals the mean of the slopes of the 3 calibration curves.

\subsection{Determination of the Stability and Specificity of the Sensor} Platform. The stability of the sensor platform was monitored every week for a period of 5 weeks by determining $0.2 \mathrm{ng} / \mathrm{mL}$ of aflatoxin $B_{1}$ as described above (Section 2.3). In order to determine the specificity of the immunosensor platform, aliquots of $0.5 \mu \mathrm{L}$ each of the interfering aflatoxin molecules such as aflatoxin $B_{2}$, aflatoxin $G_{1}$, and aflatoxin $G_{2}$ at a concentration of $1 \mathrm{ng} / \mathrm{mL}$ were mixed with $0.5 \mu \mathrm{L}$ of aflatoxin $B_{1}$ and a concentration of $0.2 \mathrm{ng} / \mathrm{mL}$ and the concentration of aflatoxin $\mathrm{B}_{1}$ estimated as described before (Section 2.3). This was repeated three times.

\section{Results and Discussion}

3.1. Development and Characterizations of the Immunosensor Platform. The sensor platform was developed as described in materials and methods (Sections 2.1 and 2.2). The first step involved an electroless plating of silver metal, which would later function as an electron transducer onto glass plates. In order to functionalize the plated silver, cysteine was linked to the silver surface via the thiol group, which, in turn, resulted in the formation of amine-terminated selfassembled monolayer of cysteine residues. The amino groups of self-assembled monolayer of the cysteine residues are thus available for conjugation to aflatoxin $\mathrm{B}_{1}$ as illustrated in Figure 2 .

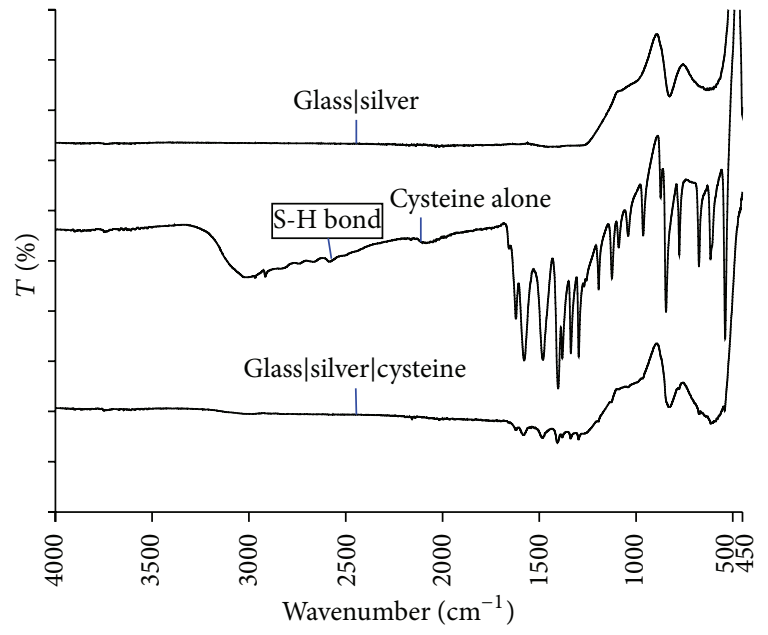

FIGURE 3: FT-IR spectra of electroless silver, cysteine, and glass|silver|cysteine demonstrating glass plated with silver, standard cysteine, and cysteine immobilized on the silver by using thiol group.

The sensor platform was characterized at every step during its development, as described in Materials and Methods (Sections 2.1 and 2.2). Fourier transmittance infrared spectra (FT-IR) was performed after every step, that is, electroless silver plating, formation of self-assembled monolayer of cysteine on silver (conjugation), conjugation of aflatoxin $B_{1}$ to cysteine group, and after blocking of the unconjugated cysteine residue sites with HRP (Figure 3). The formation of a sulfur-silver bond was demonstrated by the vanishing of a $2500 \mathrm{~cm}^{-1}$ peak of the combined spectrum of the conjugated silver/cysteine. This peak is only present in free cysteine as seen in Figure 1 (cysteine) due to the presence of thiol (S$\mathrm{H}$ ) bond. However, this peak was not recorded in the FTIR spectrum of glass-silver-cysteine, due the formation of an S-Ag bond between plated silver and cysteine instead of the $\mathrm{S}-\mathrm{H}$ bond in free cysteine $[15,16]$. Further confirmation of the presence of cysteine binding to the silver was demonstrated by carboxylate $(-\mathrm{COOH})$ stretch vibration of cysteine recorded around $1440-1640 \mathrm{~cm}^{-1}$ as shown in Figure 3. 
In order to investigate the signal transduction of assembled immunosensor, the electrical signal generation was monitored by cyclic voltammetry at each of the steps of development of the bisensor in $0.1 \mathrm{M}$ acetate buffer $\mathrm{pH}$ 6.5 containing $0.1 \mathrm{M}$ potassium chloride and $10 \mu \mathrm{M} \mathrm{H}_{2} \mathrm{O}_{2}$ (Figure 2). The unplated glass slide did not generate any redox potential over the entire scan from -1000 to $0 \mathrm{mV}$ (Figure 4(a)). The electroless-silver-plated glass [glass|silver] generated a reversible electrochemical potentialwith the anodic peak output potential magnitude of $240 \mathrm{mV}$ and cathodic peak potential of $1920 \mathrm{mV}$ and peak separation of $\sim 200 \mathrm{mV}$ at $100 \mathrm{mV} / \mathrm{s}$ (Figure 4(b)). This was because silver is a good conductor of electricity and the oxidation of silver to silver oxide and resultant reduction of silver oxide to silver led to the increase in the magnitude of redox couple [17]. However, the magnitude of the response potential decreased slightly to $160 \mathrm{mV}$ (Figure 4(c)) after conjugation of L-cysteine onto the silver. The slight decrease in response suggests that the binding of cysteine does not affect the overall electron transfer on the sensor electrode [18]. However, a large reduction was observed from $160 \mathrm{mV}$ to $-250 \mathrm{mV}$ after the binding of aflatoxin $B_{1}$ onto the sensor electrode (Figure $4(d)$ ), indicating that the binding of aflatoxin $B_{1}$ on the surface of the glass|silver|cysteine sensor electrode blocked both electron and mass transfer. Nevertheless, the peak potential was restored to $160 \mathrm{mV}$ after blocking with horseradish peroxidase (step 4; Figure 1). This could be attributed to the catalytic action of immobilised HRP that oxidize $\mathrm{H}_{2} \mathrm{O}_{2}$ to oxygen and water in a reaction accompanied by the release of 2 moles of electrons. The electrons thus generated should account for restoration of the electrical potential to $160 \mathrm{mV}$.

\subsection{Performance of the Electrochemical Immunosensor.} During the development of the sensor platform, the active sites of cysteine provided by amino groups of silver|cysteine|aflatoxin $B_{1}$ were blocked using HRP to prevent nonspecific binding of aflatoxin $B_{1}$. Hydrogen peroxide $\left(\mathrm{H}_{2} \mathrm{O}_{2}\right)$, a substrate of HRP, was used to establish whether the enzyme was bound on the free cysteine residues and thus immobilised onto the sensor electrode. Cyclic voltammogram of aflatoxin $B_{1}$ immunosensor in acetate buffer ( $\mathrm{PH}$ 6.5) in the absence (A) and presence (B) of $\mathrm{H}_{2} \mathrm{O}_{2}$ is shown in Figure 5. Although both the cathodic (reduction of silver takes place) and the anodic (oxidation of silver takes place) peaks (Figure 5(A)) observed in the absence of $\mathrm{H}_{2} \mathrm{O}_{2}$ were long-drawn-out, the same peaks (Figure 5(B)) were broadened and nonsymmetrical in the presence of $\mathrm{H}_{2} \mathrm{O}_{2}$. The long-drawn-out peaks suggested that redox reactions involving formation of silver oxide occurred on the surface of the sensor electrode [17]. Such reactions were markedly reduced, which resulted in the decrease in the cathodic and anodic peaks in the presence of $10 \mu \mathrm{M} \mathrm{H}_{2} \mathrm{O}_{2}$ (Figure 5(B)) indicative of successful binding of HRP onto the surface of the sensor electrode.

In order to test the performance of the developed sensor platform for the detection of aflatoxin $\mathrm{B}_{1}$, the sensor platform served as a working electrode and a competitive immunosensing format (Figure 1; step 5) was performed both in the absence and presence of free aflatoxin $B_{1}$ (Section 2.3). The performance of the sensor electrode in the detection of varying concentrations of aflatoxins was tested using different concentrations of aflatoxin $\mathrm{B}_{1}(0-1 \mathrm{ng} / \mathrm{L})$ and differential staircase voltammogram (DSCV) [19] was used for the determination of aflatoxin $B_{1}$ (Figure 6 ). Figure 6 shows that the DSCV currents increase with a decrease in aflatoxin $B_{1}$ concentrations, suggesting that the peak potential is inversely proportional to aflatoxin $B_{1}$ concentration. This observation suggested that the increased formation of the antigen (aflatoxin $\mathrm{B}_{1}$ ) antibody complexes with the increase in aflatoxin $\mathrm{B}_{1}$ concentration may have shielded the active sites of HRP making it inaccessible to $\mathrm{H}_{2} \mathrm{O}_{2}$. This inhibition of the breakdown of $\mathrm{H}_{2} \mathrm{O}_{2}$ should have caused a parallel decrease in electron transfer on the sensor platform [11], hence the observed inverse relation between the potentials generated as the concentration aflatoxin $B_{1}$ increase (Figure 6).

The calibration of the immunosensor platform showed that it operates within a linear dynamic range (DLR) from 0.06 to $1.1 \mathrm{ng} / \mathrm{mL}$ aflatoxin $B_{1}$ concentration, with a limit of detection (LOD) of $0.08 \mathrm{ng} / \mathrm{mL}$. A comparison of the sensor platform with other electrochemical immunosensors for aflatoxin $B_{1}$ detection is presented in Table 1 . As noted, the DLR and LOD values of the sensor platform, [glass|silver|cysteine|aflatoxin $B_{1} \mid$ HRP-blocked], compare very well and in good agreement with other immunosensors reported $[6,7,20,21]$.

3.3. Stability and Selectivity of the Immunosensor. The stability of this sensor was monitored every week for a period of five weeks. The differential staircase voltammogram (DSCV) response of the sensor changed from $1066.7 \pm 46.2 \mathrm{mV}$ to $1040 \pm 144.2 \mathrm{mV}$ which is approximately $2.5 \%$ after three weeks, and thereafter it decreased, $1000 \pm 40 \mathrm{mV}$ (which is $6.3 \%$ ) and $960 \pm 80 \mathrm{mV}$ (which is $10 \%$ ), respectively, at the fourth and fifth week (Figure 7). This suggested that the sensor platform can effectively be used for aflatoxin $B_{1}$ and determination within two weeks without loss of accuracy. Perhaps this period may be extended if the frequency of use is low.

The determination of the response of the sensor platform to interference or crossing recognition levels and to the coexisting molecules in sample was monitored as described above (Section 2.4). There was a slight interference in the detection of aflatoxin $B_{1}$ in the presence of aflatoxin $G_{2}$ (i.e., $1.44 \%$, which is $60 \mathrm{mV}$ of the $4160 \mathrm{mV}$ determined for pure aflatoxin $\mathrm{B}_{1}$ ), followed by aflatoxin $\mathrm{B}_{2}$ (i.e., $8.65 \%$, which is $360 \mathrm{mV}$ of the $4160 \mathrm{mV}$ determined for pure aflatoxin $B_{1}$ ) (Figure 8). Aflatoxin $G_{1}$ interfered more with the determinations of aflatoxin $B_{1}$ (i.e., $18.2 \%$, which is $760 \mathrm{mV}$ of the $4160 \mathrm{mV}$ determined for pure aflatoxin $B_{1}$ ) (Figure 8 ), suggesting that the two could have structural similarities especially in areas that recognize the antibodies. However, since five times the concentration of aflatoxin $B_{1}$ was used for each interfering molecule, it suggests that, in the excess of aflatoxin $B_{1}$, none of those contaminants would be detected, which, in turn, 


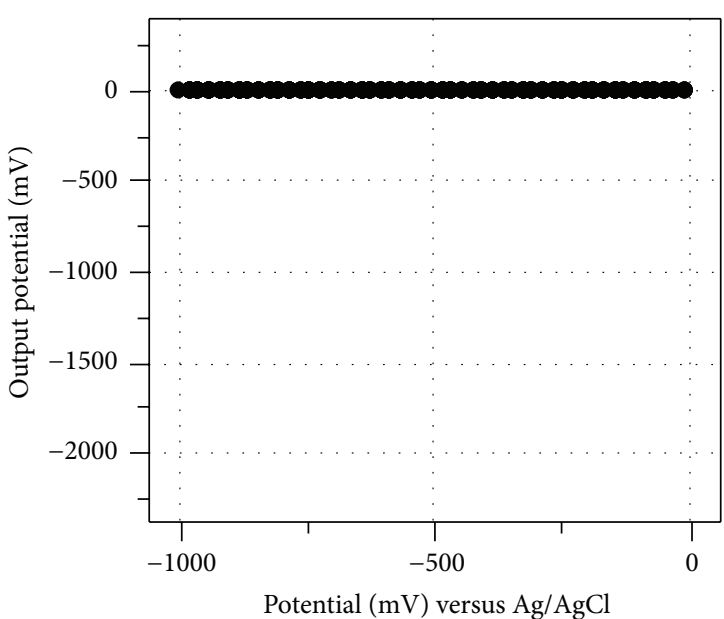

(a)

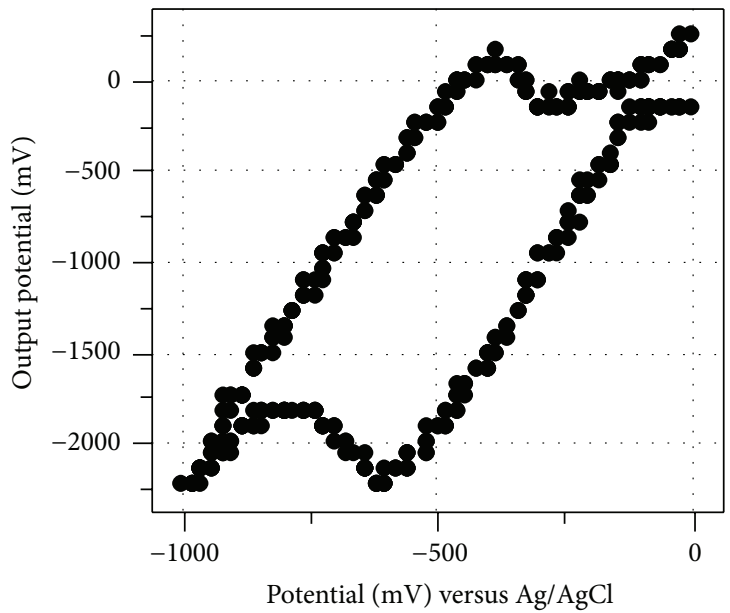

(c)

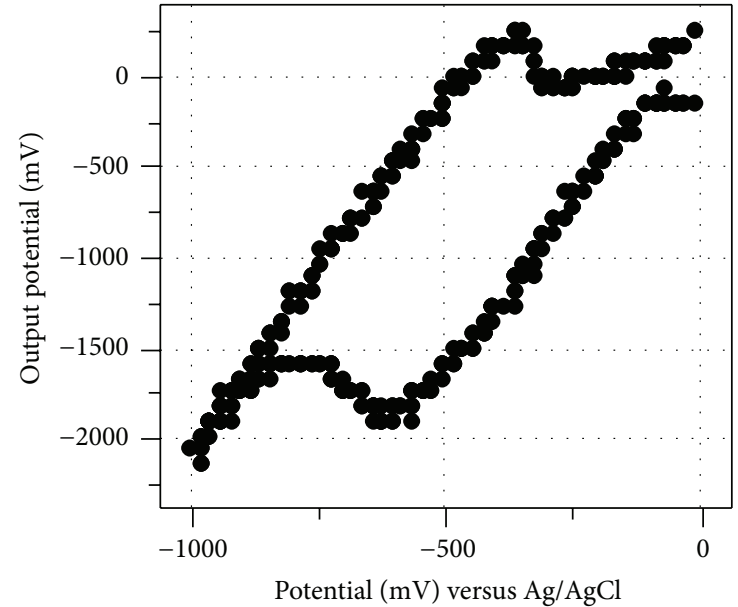

(b)

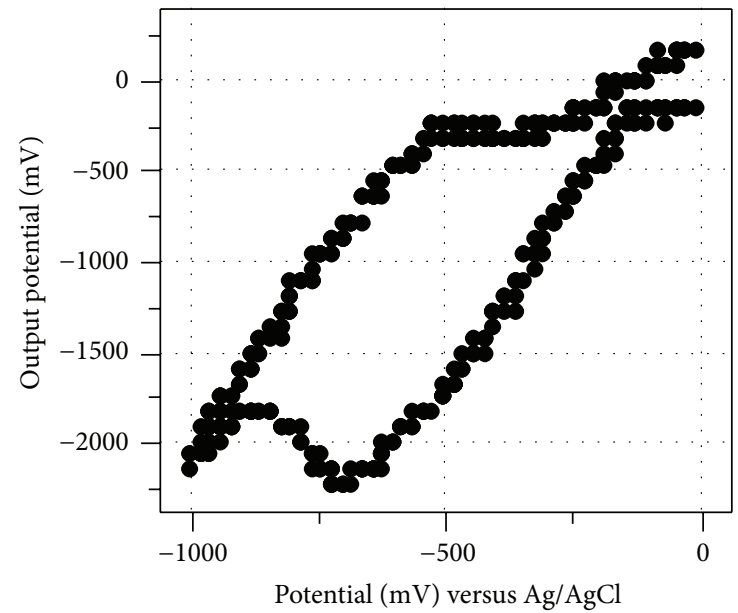

(d)

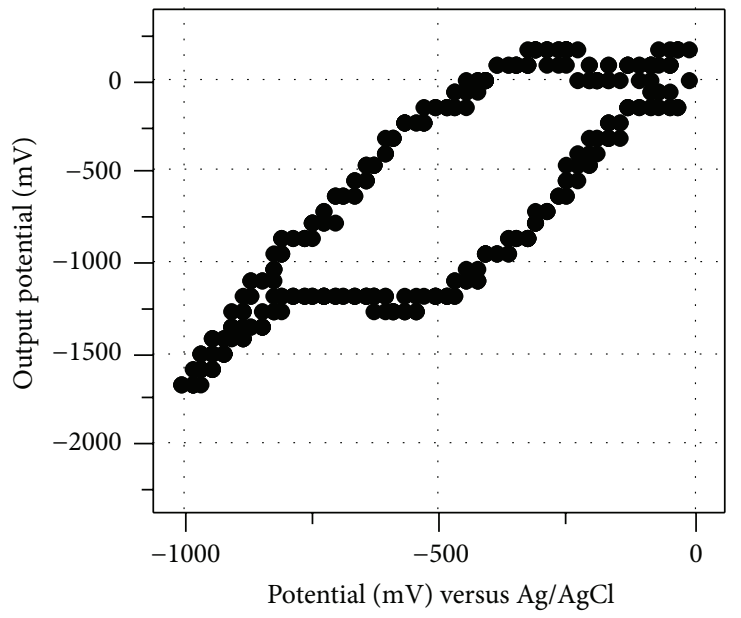

(e)

FIgURE 4: Cyclic Voltammogram of (a) bare glass; (b) glass|silver; (c) glass|silver|cysteine|; (d) glass|silver|cysteine|aflatoxin $\mathrm{B}_{1}$; (e) glass|silver|cysteine|aflatoxin $\mathrm{B}_{1} \mid \mathrm{HRP}$-blocked (Scan rate: $100 \mathrm{mV} / \mathrm{s}$ ). 
TABLE 1: Comparison of DLR and LOD of different aflatoxin $\mathrm{B}_{1}$ immunosensors.

\begin{tabular}{lccc}
\hline Electrochemical immunosensors & DLR (ng/mL) & Limit of detection $(\mathrm{ng} / \mathrm{mL})$ & Reference \\
\hline GCE/AuNP/PTH/aflatoxin $B_{1}$-BSA-conjugate/HRP-blocked & $0.6-2.4$ & 0.07 & 0.0179 \\
BSA/aAFB ${ }_{1}$-C-AuNP/MBA/Au & $0.01-0.1$ & 0.1 & {$[6]$} \\
Pt/PSSA/PANI/anti-aflatoxin B & $0.1-0.6$ & 0.2 & {$[21]$} \\
GCE/chitosan/AuNP/anti-aflatoxin B & $0.6-110$ & 0.08 & This work \\
Glass|silver|cysteine|aflatoxin $B_{1} \mid$ HRP-blocked & $0.06-1.1$ & &
\end{tabular}

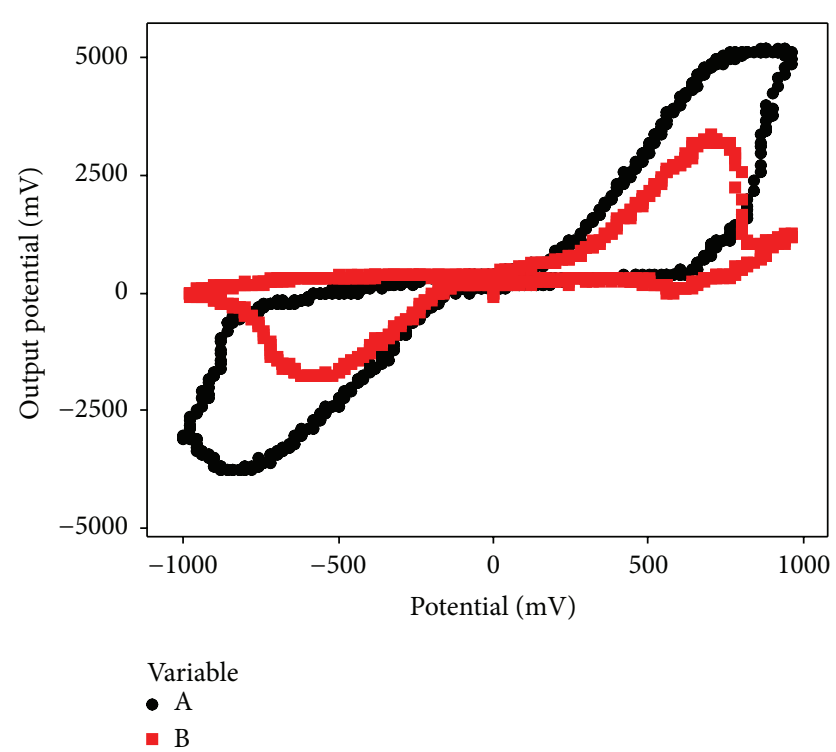

Figure 5: Cyclic voltammogram of Aflatoxin $B_{1}$ immunosensor in acetate buffer ( $\mathrm{PH}$ 6.5) in the absence (A) and presence (B) of $\mathrm{H}_{2} \mathrm{O}_{2}$ (scan rate: $100 \mathrm{mV} / \mathrm{s}$ ).

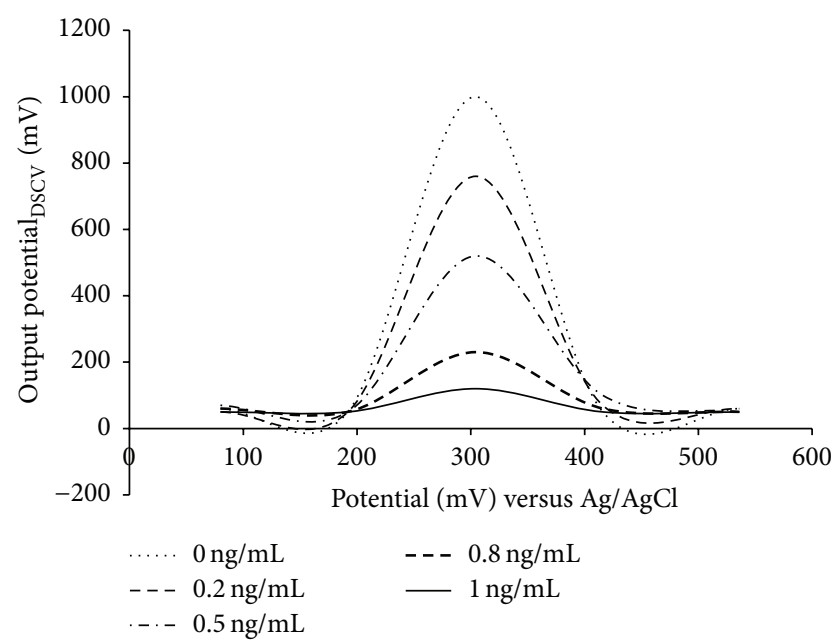

FIGURE 6: DSCV response recorded for silver|cysteine|aflatoxin $B_{1} \mid$ HRP-blocked immunoelectrode for $0-1 \mathrm{ng} / \mathrm{mL}$ of aflatoxin $B_{1}$ concentrations in a pH 6.5 acetate buffer solution (scan rate of $20 \mathrm{mV} / \mathrm{s}$ ).

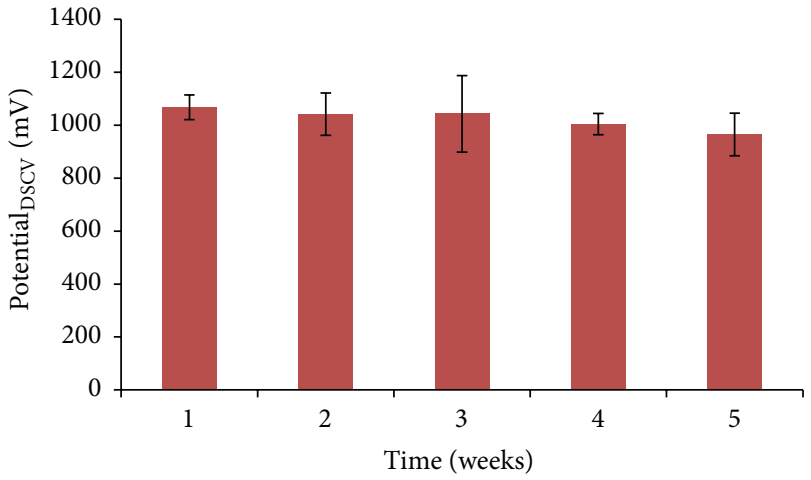

FIgURE 7: The stability of the electrochemical immunosensor observed in a period of five weeks. The differential staircase voltammogram (DSCV) response of the sensor was monitored every week for five weeks and the DSCV value was fairly stable.

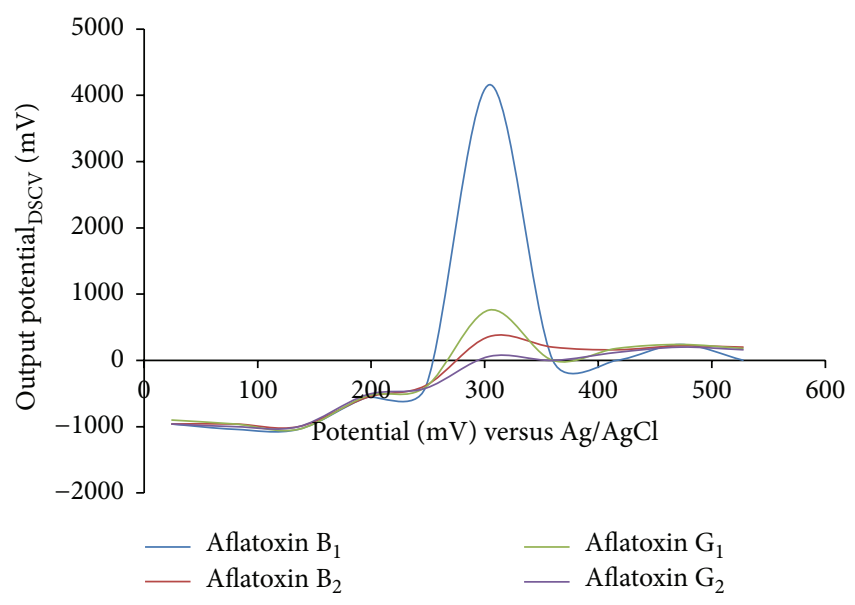

FIgURE 8: The specificity of the immunosensor platform toward aflatoxin $B_{1}$, aflatoxin $B_{2}$, aflatoxin $G_{1}$, and aflatoxin $G_{2}$.

suggests that the newly developed sensor platform is highly specific for aflatoxin $B_{1}$.

\section{Conclusion}

An electroless plated silver/cysteine sensor platform [glass|silver|cysteine|aflatoxin $\mathrm{B}_{1} \mid$ horseradish peroxidase] for the electrochemical detection of aflatoxin $B_{1}$ has successfully been developed and characterized, and its performance is 
demonstrated. The limit of detection and linear dynamic range of this sensor platform are comparable to those of other immunosensors used for aflatoxin $\mathrm{B}_{1}$ analysis. To the best of our knowledge, this is the first work that utilises electroless plated silver technology in the construction of a sensor platform for aflatoxin analyses. While these preliminary findings indicated that this immunosensor platform can be used to build an inexpensive electrochemical biosensor device for field use, this must wait for validation of its performance using HPLC as the gold standard method. This work is currently in progress.

\section{Conflict of Interests}

The authors declare that there is no conflict of interests regarding the publication of this paper.

\section{Acknowledgments}

The authors acknowledge the financial support from the Canadian International Development Research Council (IDRC) and Uganda Industrial Research Institute (UIRI), and the technical support from the Department of Chemistry, UIRI, and the Department of Chemistry, Uganda Bureau of Standards (UNBS).

\section{References}

[1] A. P. Wacoo, D. Wendiro, P. C. Vuzi, and J. F. Hawumba, "Methods for detection of aflatoxins in agricultural food crops," Journal of Applied Chemistry, vol. 2014, Article ID 706291, 15 pages, 2014.

[2] A. Sargent and O. A. Sadik, "Monitoring antibody-antigen reactions at conducting polymer-based immunosensors using impedance spectroscopy," Electrochimica Acta, vol. 44, no. 26, pp. 4667-4675, 1999.

[3] J. J. Langone and H. Van Vunakis, "Aflatoxin B; specific antibodies and their use in radioimmunoassay," Journal of the National Cancer Institute, vol. 56, no. 3, pp. 591-595, 1976.

[4] D. Babu, Rapid and Sensitive Detection of Aflatoxin in Animal Feeds and Food Grains Using Immunomagnetic Bead Based Recovery and Real-Time Immuno Quantitative Pcr (Rt-iqpcr) Assay, Oklahoma State University, 2010.

[5] D. R. Thevenot, K. Toth, R. A. Durst, and G. S. Wilson, "Electrochemical biosensors: recommended definitions and classification," Pure and Applied Chemistry, vol. 71, pp. 23332348, 1999.

[6] J. H. O. Owino, O. A. Arotiba, N. Hendricks et al., "Electrochemical immunosensor based on polythionine/gold nanoparticles for the determination of aflatoxin $\mathrm{B}_{1}$," Sensors, vol. 8, no. 12, pp. 8262-8274, 2008.

[7] L. Masoomi, O. Sadeghi, M. H. Banitaba, A. Shahrjerdi, and S. S. H. Davarani, "A non-enzymatic nanomagnetic electroimmunosensor for determination of aflatoxin $\mathrm{B}_{1}$ as a model antigen," Sensors and Actuators B: Chemical, vol. 177, pp. 11221127, 2013.

[8] Z. Linting, L. Ruiyi, L. Zaijun, X. Qianfang, F. Yinjun, and L. Junkang, "An immunosensor for ultrasensitive detection of aflatoxin $B_{1}$ with an enhanced electrochemical performance based on graphene/conducting polymer/gold nanoparticles/the ionic liquid composite film on modified gold electrode with electrodeposition," Sensors and Actuators, B: Chemical, vol. 174, pp. 359-365, 2012.

[9] Y. Liu, Z. Qin, X. Wu, and H. Jiang, "Immune-biosensor for aflatoxin $\mathrm{B}_{1}$ based bio-electrocatalytic reaction on micro-comb electrode," Biochemical Engineering Journal, vol. 32, no. 3, pp. 211-217, 2006.

[10] N. Adányi, I. A. Levkovets, S. Rodriguez-Gil, A. Ronald, M. Váradi, and I. Szendrö, "Development of immunosensor based on OWLS technique for determining Aflatoxin B1 and Ochratoxin A," Biosensors and Bioelectronics, vol. 22, no. 6, pp. 797-802, 2007.

[11] S. J. Daly, G. J. Keating, P. P. Dillon et al., "Development of surface plasmon resonance-based immunoassay for aflatoxin $\mathrm{B}_{1}$," Journal of Agricultural and Food Chemistry, vol. 48, no. 11, pp. 5097-5104, 2000.

[12] L. Dunne, S. Daly, A. Baxter, S. Haughey, and R. O’Kennedy, "Surface plasmon resonance-based immunoassay for the detection of aflatoxin $\mathrm{B}_{1}$ using single-chain antibody fragments," Spectroscopy Letters, vol. 38, no. 3, pp. 229-245, 2005.

[13] J. H. Byeon and J.-W. Kim, "Fabrication of a pure, uniform electroless silver film using ultrafine silver aerosol particles," Langmuir, vol. 26, no. 14, pp. 11928-11933, 2010.

[14] A. Antonello, B. Jia, Z. He et al., "Optimized electroless silver coating for optical and plasmonic applications," Plasmonics, vol. 7, no. 4, pp. 633-639, 2012.

[15] J. H. Priester, A. Singhal, B. Wu, G. D. Stucky, and P. A. Holden, "Integrated approach to evaluating the toxicity of novel cysteine-capped silver nanoparticles to Escherichia coli and Pseudomonas aeruginosa," Analyst, vol. 139, no. 5, pp. 954-963, 2014.

[16] A. C. Templeton, S. Chen, S. M. Gross, and R. W. Murray, "Water-soluble, isolable gold clusters protected by tiopronin and coenzyme a monolayers," Langmuir, vol. 15, no. 1, pp. 66-76, 1999.

[17] Y.-J. Choi and T.-J. M. Luo, "Electrochemical properties of silver nanoparticle doped aminosilica nanocomposite," International Journal of Electrochemistry, vol. 2011, Article ID 404937, 6 pages, 2011.

[18] Y. Liu and C. Feng, "A sensitive potentiometric immunosensor based on nano-gold/cysteine/nafion-modified platinum disk electrode," International Journal of Digital Content Technology and its Applications, vol. 7, no. 7, pp. 569-577, 2013.

[19] F. Scholz, L. Nitschke, and G. Henrion, "Differential staircase voltammetry - a new electroanalytical technique," Fresenius' Zeitschrift für Analytische Chemie, vol. 332, no. 7, pp. 805-808, 1988.

[20] A. Sharma, Z. Matharu, G. Sumana, P. R. Solanki, C. G. Kim, and B. D. Malhotra, "Antibody immobilized cysteamine functionalized-gold nanoparticles for aflatoxin detection," Thin Solid Films, vol. 519, no. 3, pp. 1213-1218, 2010.

[21] J. H. O. Owino, A. Ignaszak, A. Al-Ahmed et al., "Modelling of the impedimetric responses of an aflatoxin B1 immunosensor prepared on an electrosynthetic polyaniline platform," Analytical and Bioanalytical Chemistry, vol. 388, no. 5-6, pp. 1069-1074, 2007. 


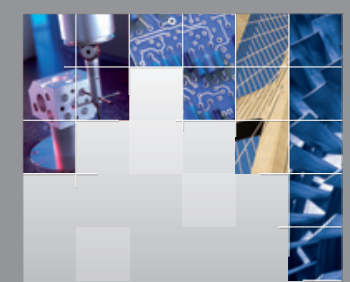

\section{Enfincering}
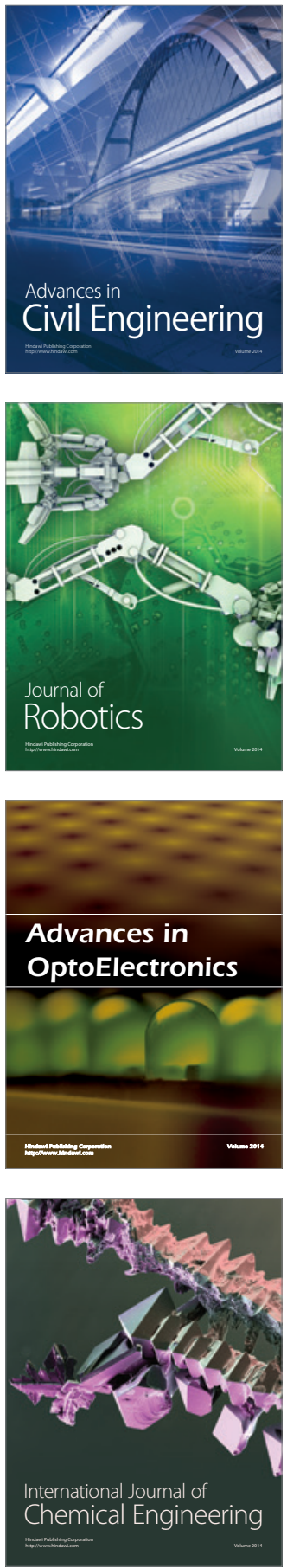

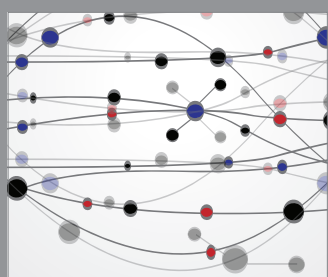

The Scientific World Journal

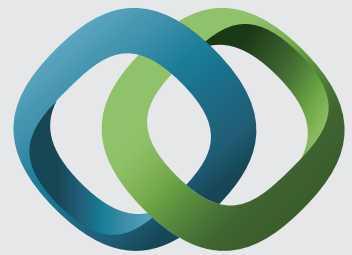

\section{Hindawi}

Submit your manuscripts at

http://www.hindawi.com
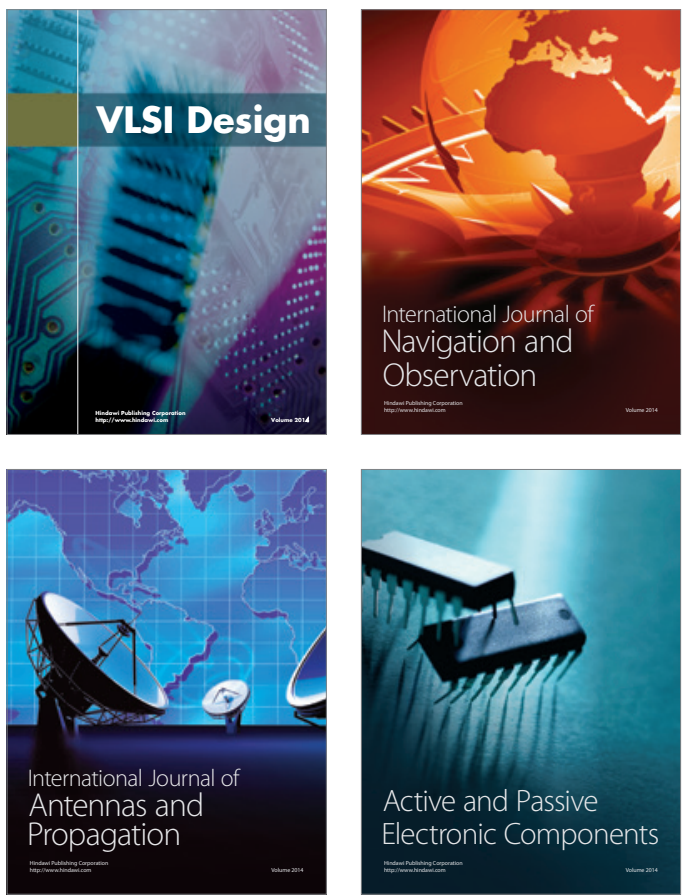
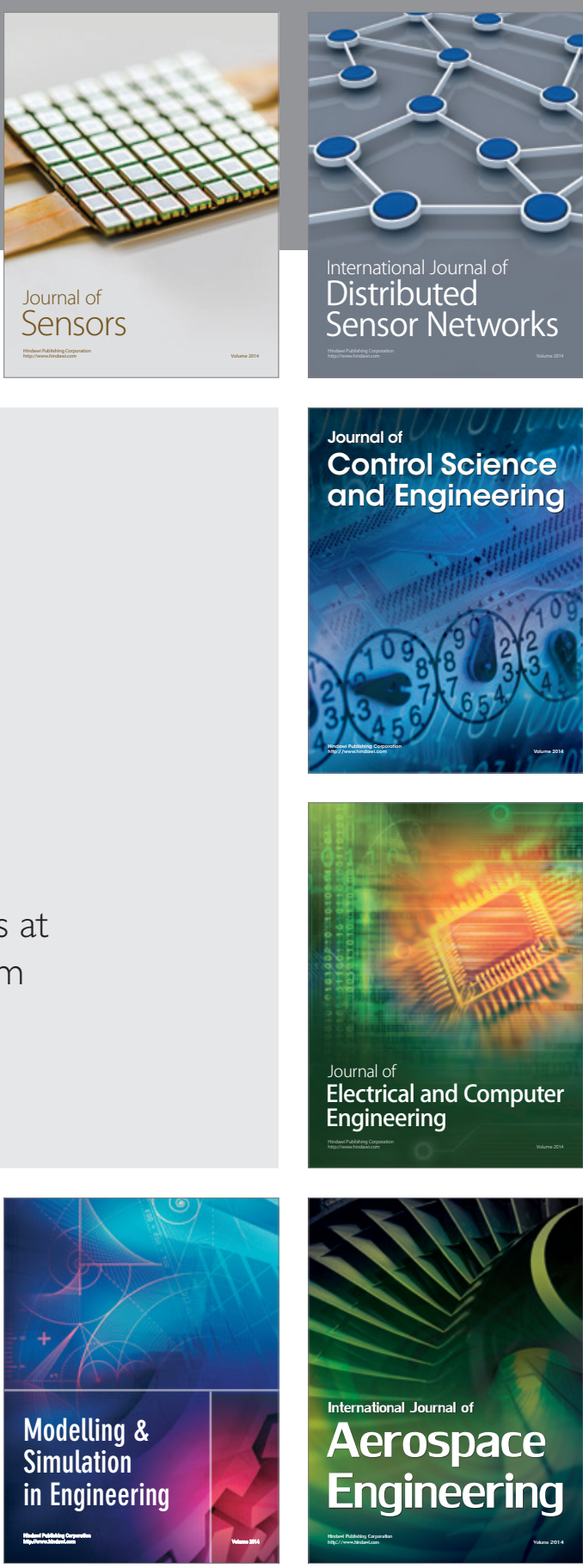

International Journal of

Distributed

Sensor Networks

Journal of

Control Science

and Engineering
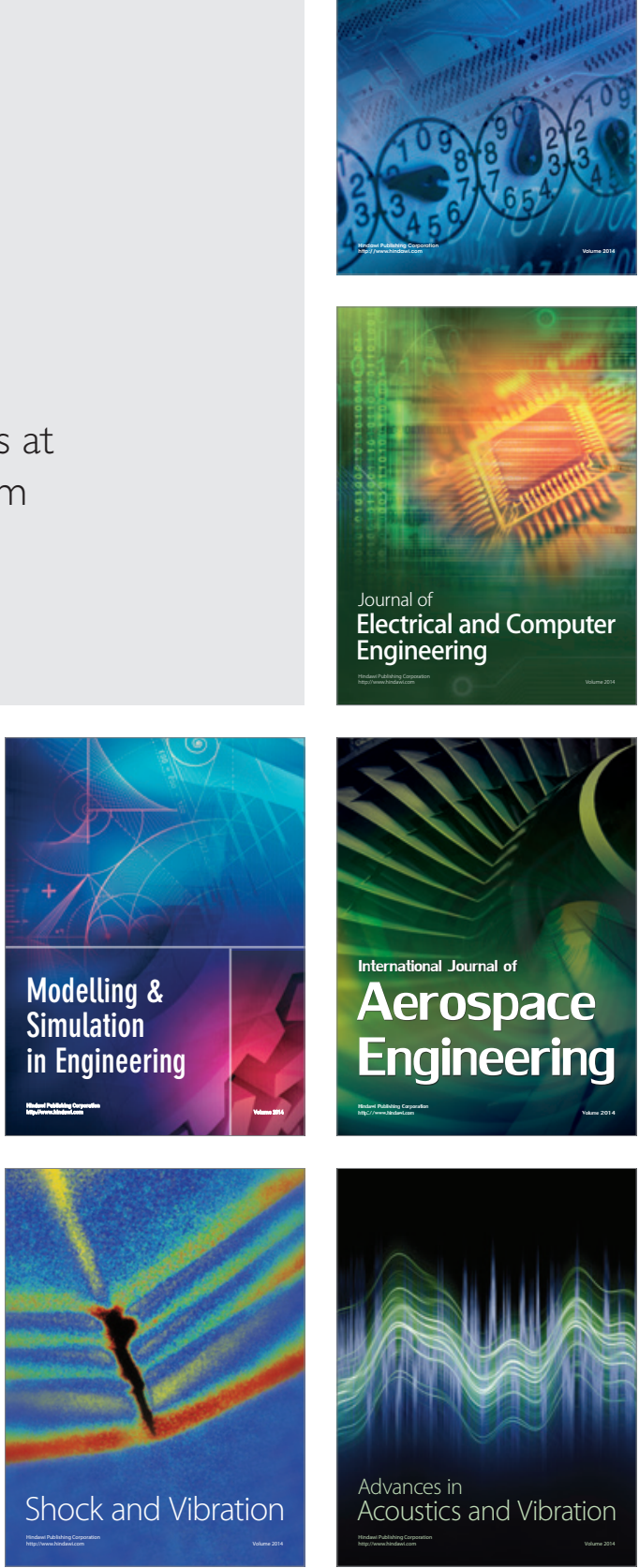